\title{
The World in a Book: Al-Nuwayri and the Islamic Encyclopedic Tradition
}

Elias Muhanna

Princeton: Princeton University Press, 2018, 232 sayfa.

ISBN 9780691175560

Kitap, yazarın Harvard Üniversitesi'nde 2012 yılında tamamladığ Encyclopaedism in the Mamluk Period: The Composition of Shihäb al-Din al-Nuwayrìs (d. 1333) 'Nihāyat al-Arab fì Funūn al-Adab' başlıklı doktora tezinin geliştirilmiş halidir. Çalışma, Memlükler dönemi literatürü içerisinde en hacimli ve ihtiva ettiği konular bakımından en kapsamlı eserlerden biri kabul edilen Nihâyetü'l-ereb fî fünûni'l-edeb'in üretildiği kültürel ortama, kaynaklarına, konu tasnifine, inşâ ve telif usullerine dair dikkatli bir inceleme sunmaktadır. Eserin müellifi Şehâbeddin en-Nüveyrînin (ö. 733/1333) ulema, ilim kurumları, Memlük idarecileri, idarî teşkilatı ve bürokratik mansıpları arasında geçen çok yönlü hayatı da titizlikle bu incelemeye dahil edilmektedir.

Muhanna'nın tespitlerine göre otuz bir ciltte dokuz bin küsur sayfa ve iki milyonun üzerinde kelimeden oluşan Nihâyetü'l-ereb (s. 1, 106), sadece hacminin büyüklügü ile değil kozmoloji, insan, hayvanlar, bitkiler ve tarih olmak üzere beş ana başlık ( $f e n)$ altında çeşitli ilimlere dair bilgileri bir araya getiren muhtevasının genişliği ile de dikkat çekmektedir. Nüveyrînin niçin böyle bir eser telif ettiği, eserine hangi ilimlerin konularını dahil ettiği, eserin telifinde hangi örnekleri model aldığı, hangi kaynakları kullandığı, telif sırasında hangi çalışma usullerine başvurduğu, eserin Nüveyrînnin çağdaşları tarafından ne ölçüde tanındığı, müellifin vefatından günümüze İslâm dünyasında ve Avrupa’da okurları tarafından nasıl değerlendirildiği gibi meseleler çalışmanın temel sorularını oluşturmaktadır.

Kitabın birinci bölümü, en önemli örnekleri XIII. yüzyıldan XV. yüzyıla kadar Mısır ve Şam coğrafyasında görülen ansiklopedik telif türünün mahiyetini incelemektedir. Muhanna’nın "ansiklopedik" sıfatını iliştirdiği eserler dil, edebiyat, şiir, inşâ, tabakat, tarih, coğrafya, astronomi, fikıh, hadis, tıp, felsefe, botanik, zooloji gibi farklı alanların literatüründen faydalanılarak telif edilmişlerdir. Bu bölümde, Memlükler dönemi literatüründe ansiklopedi dendiğinde ne anlaşılması gerekir, bu bir türe mi yoksa telif özelliğine mi işaret eder, Avrupa'da gelişen ansiklopedi türü ile benzerlikleri ve farklılıkları nelerdir gibi sorular etrafında kavramsal bir tartışma yapılmaktadır. Avrupa’da ansiklopedi türünün tarihi her ne kadar XV. yüzyılda üretilen Latince bazı 
eserlere kadar götürülmek istense de yazara göre objektiflik, multi-disiplinerlik, kuşatıcılık ve sistematik organizasyon gibi modern kullanımda ansiklopediye izafe edilen özellikler bu kitaplarda bulunmamaktadır (s. 9-10). Modern tarih yazımında, Avrupa'da dahi ansiklopedi türünün gelişimi ve mahiyeti hakkında bir uzlaşı yokken bu kavram, Arapça literatürdeki bazı eserler için nasıl kullanılabilir? Bu problemin farkında olan yazar, modern öncesi dönemde üretilen bazı Arapça metinleri anlamlandırmak için bir tür olarak ansiklopedi terimini kullanmaktansa daha soyut ve yorumlama kapasitesi daha yüksek olan "ansiklopedizm" ve "ansiklopedik" kavramlarını teklif etmektedir. "Ansiklopedizm", kuşatıcılık ve sistemli bilgi tasnifini bir arada ifade eden bir kavram olarak tasavvur edilirken "ansiklopedik" sıfatı bu özelliklere sahip eserlere iliştirilmektedir. Yazar bu şekilde, modern bir tür anlamında ansiklopedi terimini kullanmaktan kaçındığını, ancak teklif ettiği bu kavramlarla bahsi geçen özellikleri taşıyan eserler hakkında konuşabilmek ve bunları yorumlayabilmek adına bir zemin oluşturma imkânı bulduğunu ifade eder (s. 11-12). Bu bağlamda kitap boyunca Nüveyrînin Nihâyetü’lereb'i, "Memlük ansiklopedizmi" içerisinde konumlanan "ansiklopedik" bir eser olarak ele alınmaktadır.

Kitapta, Memlük tarihi ve literatürü üzerine çalışan hemen her araştırmacının zihnini meşgul eden, "Niçin tam olarak bu dönemde ve bu coğrafyada bu kadar çok ve çeşitli eser telif edildi?" sorusu tartışmaya açılmaktadır. Muhanna, özellikle ansiklopedik telifler söz konusu olduğunda modern literatürde bu soruya verilen cevapların üç ana başlık altında değerlendirilebileceğini ifade eder. Birincisi, XIX. yüzyllın hâkim oryantalist tezi olan ve özellikle Moğol istilasından sonraki dönemi bir kültürel çöküş ve gerileme dönemi olarak yorumlayan yaklaşımdır. Son yıllarda bu dönem üzerine yapılan ayrıntılı araştırmalar sayesinde bu yaklaşımın geçerliliğini yitirdiğini ifade eden yazar, daha yoğun bir şekilde kritik edeceği ikinci yaklaşıma geçmektedir. Buna göre Memlükler dönemi müellifleri, Moğol istilası sırasında yaşanan kütüphanelerin yıkılması ve kitapların tahrip edilmesi gibi sarsıcı olaylardan etkilenip bütün bilginin yitip gitmesinden korktukları için mevcut kültürel birikimi muhafaza etme duygusu içerisinde eserlerini telif etmişlerdir. Muhanna’ya göre medeniyet mirasının ve antik bilginin yok olmasi$\mathrm{n} ı$ önlemek için tedbir alma ihtiyacı ile ansiklopedik metinlerin üretilmesi arasında kurulan ilişki, Avrupa'da ansiklopedi türünün doğuşunu açıklamak için kullanılmaktadır; fakat Memlük müellifleri böyle bir motivasyonla eser telif etmemişlerdir. Bu iddiasını desteklemek için şu argümanları sıralamaktadır: Bağdat kütüphanelerindeki kitapların Dicle nehrine atıldığı ve nehrin suyunun mürekkep renginde aktığı şeklindeki tasvir, yerel ve olaya şahitlik 
eden kaynaklarda yer almayıp daha sonra üretilen efsanevî anlatılara dayanmaktadır. Bağdat, Moğol istilasından çok daha önce bir kültür ve medeniyet merkezi olma özelliğini yitirmiştir. Son olarak Nüveyrînnin otuz bir ciltlik eserinde ve hususen Moğollar’ı ele aldığı bölümde onun kültürel birikimin yok olmasından endişe duyduğuna dair herhangi bir ibare yer almamaktadır (s. 17). Yazarın argümanları dikkat çekici olmakla birlikte Memlükler dönemi müelliflerinin Moğol istilasının sebep olduğu kültürel yıkımdan hiçbir şekilde etkilenmediklerini söylemek mümkün görünmemektedir. Zira bu yıkım hakkındaki tasvirler, muahhar kaynaklarda yer alan efsanevi anlatılardan ibaret olsa bile müelliflerin olaya dair hissiyatını yansıtması bakımından önemlidir. Bu bağlamda Tâceddin es-Sübkînin (ö. 771/1370) Moğol istilası ve etkilerine Tabakāt'inda yer ayırması; İslâm dünyasının doğusunda Şâfiî fukahanın bulunduğu beldelerin harap edilmesinden, camilerin, medreselerin, kütüphanelerin tahrip edilerek kitapların yakılmasından bahsetmesi ve fakihlerin bu olaylar hakkında bilgi sahibi olup ibret almaları gerektiğini belirtmesi özellikle dikkate değerdir. ${ }^{1}$

Muhanna’ya göre Moğol istilası, doğudan batıya ulema hareketliliğine sebep olarak sosyolojik bir etkide bulunmuş olmakla birlikte Memlük müelliflerinin eser üretimine motivasyon sağlamak gibi psikolojik bir etkide bulunmamıştır. Kitabın temel tezi tam bu noktada belirmektedir: İlim kurumları ile donatılmış olan Memlük şehirlerinde ulemanın yanı sıra üretilen ve dolaşımda olan eserlerin sayısında da büyük bir artış yaşanmış ve bu durum bilginin sınırlarını genişletmiştir. Bu şartlar altında müellifler, çok fazla bilgiyle başa çıkma problemini, telif için yeni formlar geliştirip kuşatıcı metinler üreterek aşmaya çalışmışlardır (s. 19).

Memlükler döneminde ansiklopedik teliflerin sayısında yaşanan artışı açıklamaya çalışan üçüncü yaklaşım ise bu eserlerle kâtiplik ve inşâ kültürü arasında irtibat kurmaktadır. Buna göre Memlükler döneminde inşâa divanı, eğitim kurumlarının yanında bilginin nakledilmesi ve uzmanlıkları birbirinden farklı çok sayıda âlimin birbiriyle temasa geçmesi için önemli bir alan sunmaktaydı (s. 20). Yazar, Memlükler döneminde üretilen ansiklopedik teliflerle inşâ sanatına dair eserlerin müelliflerinin aynı olması ve başta Nihâyetü̉l-ereb olmak üzere ansiklopedik teliflerin inşâ alanına geniş yer ayırmasından hareketle üçüncü yaklaşıma yakın durmaktadır. Ancak bu yaklaşımı geliştirerek ansiklopedik teliflerin, ulemanın ilmî pratikleri ile kâtiplerin inşâ pratiklerini birleştiren bir dünyanın ürünü olduğunu öne sürmektedir. Burada Thomas Bauer'in görüşlerine atıfla Abbâsîler döneminden

1 Sübkî, Tabakāt, I, 328-42. 
itibaren kâtipler eliyle geliştirilen âdab literatürü ile ulema tarafından üretilen eserler arasında Memlükler döneminde bir bütünleşme yaşandığını ifade etmektedir. Memlükler döneminde kâtipler, ulemadan ayrı bir grup teşkil etmedikleri gibi kâtiplerin görev yaptığı idarî mansıplara tayin edilenler, hem inşâya dair teorik ve pratik bir eğitimden geçmiş hem de ilim kurumlarında tedris edilen ilimleri tahsil etmiş kimselerdi. Bauer'e göre Memlükler döneminde, âdab literatürünün ulema tarafından şekillendirildiği (ulamaization of adab), ulemanın telif ettiği eserlerde ise âdab literatürünün üslubunun belirgin hale gelmeye başladığı (adabization of ulama) bir süreç yaşanmıştır (s. 22). Muhanna’ya göre bu birliktelik ansiklopedik teliflerin üretilmesi için gerekli zemini ve motivasyonu sağlamıştır.

Kitabın ikinci bölümünde Nihâyetü'l-ereb bir bütün olarak incelenmekte, metnin konu tasnifi, tematik akışı, hangi bölümünün hangi ilimlerle irtibatlı olduğu, âdab literatürünün diğer örnekleri ile mukayese edildiğinde eserin ne gibi benzerlikler ve farklılıklar taşıdığı ele alınmaktadır. Bu bölüm Nihâyetü’lereb'in telif tarzına ve bir şekilde bağlı olduğu telif türleri arasındaki yerine ilişkin bazı önemli bulgular içermektedir. Öncelikle yazar, Nüveyrînin eserini, özenle tasarlanmış bir hiyerarşik düzen üzerine inşa ettiğini vurgulamaktadır. Kitap beş fenden oluşmakta her fen, beş kısıma ayrılmakta, her kısım beş bâba ayrılmakta bu bâblar altında da çeşitli düzeyleri olan alt başlıklar yer almaktadır. Yazara göre Nüveyrî, son derece hacimli olan eserinde bu hiyerarşi sayesinde bir düzen oluşturabilmiştir (s. 31). Bölümdeki bir diğer önemli tespit, Nüveyrînin, kitabın her bölümünde o bölümde ele aldığı konuya sadık kaldığının ve bu bağlamda konunun şiir, edebiyat, tarih vb. alanları ilgilendiren uzanımları varsa metin-içi referansları yoğun bir şekilde kullanarak okuru ilgili bölümlere yönlendirdiğinin belirtilmesidir. Yazara göre Nüveyrînnin başarılı bir şekilde uyguladığı metin-içi referans yöntemi, onun farklı bilgi türlerini birbiriyle irtibatlandırmadaki maharetini ve zihnindeki ilimler tasnifini de ortaya koymaktadır (s. 35).

Muhanna, dijital imkanları etkili bir şekilde kullanıp ${ }^{2}$ emek mahsulü bir çalışma yaparak Nihâyetü’l-ereb'in her bölümü için kelime sayımı yapmış ve hangi bölümün kitabın yüzde kaçını oluşturduğunu tespit etmiştir. Buna göre beş üst-başlık ( $f e n)$ arasından tarih başlı̆̆ı eserin hacminin yüzde yetmişini oluşturmaktadır. Yazara göre bu durum, müellifi tarafından bir âdab kitabı olarak tasarlanan Nihâyetü'l-ereb' in çağdaşları ve sonraki okurları tarafından niçin bir tarih kitabı olarak tanınmış olduğunu da açıklamaktadır (s. 36-37).

2 İslâm araştırmalarında dijital araçların sunduğu imkânlara dikkat çeken, yazarın editörlüğünü yaptığ 1 ve bir makaleyle katkıda bulunduğu çalışma için bk. The Digital Humanities. 
Ayrıca yazar, Nüveyrînin hâkim tarih tasnif usulü olan yıllara göre tasnifi bilinçli bir şekilde terkederek devletler ve hanedanlara göre tasnif usulünü benimsediğini, bunlardan her birinin tarihini müstakil bir bölüm içerisinde baştan sona ele alarak okurlarına daha az tekrar içeren alternatif bir okuma biçimi sunduğunu ifade etmektedir (s. 48-49).

Kitapta Nihâyetü'l-ereb, Abbâsî döneminden itibaren telif edilen klasik âdab eserleriyle muhtevası ve konu tasnifi bakımından mukayese edilmiştir. İbn Kuteybe’nin (ö. 276/889) Uyûnül-ahbâr'ı ve İbn Abdürabbih'in (ö. 328/940) el-íkdü'l-ferîd'i gibi sekiz eseri incelemesine dahil eden yazar, Nihâyetül-ereb'in hacminin genişliği, başvurduğu kaynakların çeşitliliği ve çokluğu, bahsi geçen literatürdeki dağınık malzemeyi hiyerarşik tasnif usulü sayesinde ahenkli hale getirmesi gibi açılardan klasik âdab literatüründen ayrıldığını öne sürmektedir (s. 40-42). Muhanna’ya göre Nihâyetüll-ereb'i ansiklopedik bir telif haline getiren hususların başında, âdab türünün alanını genişleterek onu çok sayıda ilim ve türü içine alan bir şemsiye haline getirmesi gelmektedir. Bu durum, Memlükler dönemi ansiklopedik teliflerinin diğer iki önemli örneğinde de görülebilir. Bunlardan İbn Fazlullah el-Ömerînin (ö. 749/1349) Mesâlikül-ebsâr fî memâliki'l-emsâr’’ bir coğrafya kitabı olarak tasarlanmış, ancak bu türün geleneksel sınırlarını aşarak farklı ilimlere ait çok sayıda konuyu bir araya getirmiştir. Kalkaşendî ise (ö. 821/1418) Subhu'l-a ‘şâ fì sınâati'l-inşâ adlı kitabını inşâ türünde telif ettiğini ifade etse de kitapta kozmoloji, coğrafya, fikıh, tarih vb. farklı türler içerisinde yer alan malzemeyi bir araya getirmiştir (s. 51).

Kitabın üçüncü bölümü, Nihâyetü'l-ereb'in kaynaklarını ele almaktadır. Müellif hattı otuz bir cilt olan bir eserin her bölümünün kaynaklarını tespit eden bir araştırma yapmak kolay değildir. Muhanna, eserin yaklaşık onda birini oluşturan kozmoloji, hayvanlar ve bitkiler bölümünün kaynaklarını çıkartmaya çalışmış ve bu bölümlerin hem konu tasnifi hem de muhteva bakımından Cemâleddin el-Vatvât'in (ö. 718/1318) ansiklopedik eseri Mebâhicülfiker ve menâhicüll-iber'ine dayandığını tespit etmiştir (s. 67). Eserin kalan yüzde doksanlık kısmını oluşturan insan ve tarih bölümlerinin bazı temel kaynaklarını sıralamakla birlikte bütün kaynaklarını tespit etmenin her zaman mümkün olmadığını ifade etmiştir (s. 69-70). Kitabın, Nihâyetü'l-ereb'i bir bütün olarak incelemede başarılı olduğu, ancak eserin yaklaşık yüzde yetmişini oluşturan tarih bölümünün kaynaklarını tespit edip müellifin bu bölümdeki tercihlerini ve telif usulünü açıklamada yetersiz kaldığı görülmektedir. Bu anlamda Nihâyetü'l-ereb'in hacimli ve telif tarzı bakımından orijinal özellikler taşıyan tarih bölümü, ayrıntılı araştırmalara konu edilmeyi beklemektedir. 
Kitapta Nüveyrînin hayatı, ilim tahsili ve tayin edildiği idarî mansıplar da incelenmekte, bu serüvenin Nihâyetül-ereb’e hangi açlardan kaynaklık etmiş olabileceği tartışılmaktadır. Muhanna’nın tespitine göre Nüveyrî, vefatına kadar Kahire'nin en görkemli medreselerinden biri olan Nâsıriyye’nin bir hücresinde kalmış, bu kurumun nâzırlığını yapmış ve muhtemelen Nihâyetül-ereb'i burada telif etmiştir (s. 57). Bu medresenin hemen yakınında bulunan Mansûriyye Bîmâristanı'nda da nâzırlık görevini sürdürmüştür. Yazara göre Nüveyrî, bu kurumlarda görev yapan müderrislerden, öğrencilerden, düzenlenen derslerden ve bu kurumların kütüphanelerinden yoğun bir şekilde faydalanmış olmalıdır. Özellikle tıp, zooloji ve ilaçlar konusunda sahip olduğu ve kendi şahitliğine dayanan bilgileri, Mansûriyye Bîmâristanı'nda edinmiş olması kuvvetle muhtemeldir (s. 63-65). Nüveyrînin ilim kurumları dışında tayin edildiği diğer yüksek dereceli idarî mansıplar ise kitabın dördüncü bölümünde incelenmektedir. Burada idarî mansıpların, Memlükler dönemi müelliflerine sosyal, siyasî ve ekonomik ağlar sunmanın yanında kayıt tutma, not alma ve bunları tasnif etme gibi inşâ pratikleri kazandırdığı ileri sürülmektedir. Ayrıca yazar, idarî mansıpların, ansiklopedik eserlerin müelliflerine toplumun farklı alanları ve temsilcileri ile temas kurma imkânı verdiğini, bu sayede onların eserlerinde, yaşadıkları döneme ilişkin tutarlı ve güvenilir kayıtlar tutabildiklerini öne sürmektedir (s. 90-91).

Dikkatle riayet edilen çok katmanlı bir hiyerarşiye sahip olan Nihâyetü'lereb, yüzlerce kaynaktan nakiller içermekte ve çok sayıda metin içi referans barındırmaktadır. Muhanna, çalışmanın beşinci bölümünde, Nüveyrînin böyle bir eseri nasıl yazıya geçirdiğini ve bu konudaki çalışma usulünü anlamaya çalışmaktadır. Müellifin, çağdaşları tarafından usta bir müstensih olarak tanındığının ve istinsah ettiği nüshaların çok değerli kabul edildiğinin altını çizen yazar, onun Nihâyetü'l-ereb'i yazmadan önce müsveddeler hazırladığını ardından da en ufak bir kalem sürçmesi dahi olmayan muntazam nüshalar oluşturduğunu düşünmektedir (s. 108). Çalışmanın bu bölümü için yazma katalogları incelenerek eserin otuz müellif hattı nüshası tespit edilmiştir. Yazar, Avrupa kütüphanelerinde bulunan on dört nüsha üzerinde çalıştığını, ancak İstanbul kütüphanelerinde bulunan on altı nüshayı inceleyemediğini ifade etmektedir ki bu durumun, çalışmanın önemli eksiklerinden biri olduğu söylenebilir (s. 112).

Kitabın son bölümü, telif edildiği dönemden modern döneme kadar Nihâyetüll-ereb'in okurları tarafından nasıl değerlendirildiğini incelemektedir. Muhanna’ya göre hacmi ve muhtemel maddi değeri düşünüldügünde isteyen her okurun eserin tamamına sahip olması mümkün değildi. $\mathrm{Bu}$ 
yüzden eserin okurlarının çoğu, muhtemelen kendi ilgilendikleri alanla ilgili ciltleri istinsah etmiş ya da ettirmiş olmalıdırlar. Eserin her cildinin müstakil olarak okunulabilecek şekilde tasarlanmış olması da bu ihtimali güçlendirmektedir (s. 124). Kitabın bu bölümünde, ayrıca Nihâyetü'l-ereb'in nüshalarının Avrupa kütüphanelerine intikal süreci kronolojik olarak incelenmekte, bu sürecin aktörleri ve onların eser üzerindeki çalışmaları hakkında bilgi verilmektedir.

Yazarın, çalışma boyunca, bir eseri ansiklopedik kılan nedir sorusuna açı ve sınırları tanımlanmış bir cevap verdiğini söylemek zordur. Ancak kitapta dağınık halde bulunan yaklaşımlarından hareketle onun, farklı telif türlerini bir şemsiye altında buluşturan, çeşitli ilimlere dair konuları bir araya getiren, konu tasnifinde hiyerarşik bir düzen benimseyerek sistemli bilgi tasnifi sunan ve güçlü bir metin-içi referans örgüsüne sahip olan eserleri "ansiklopedik" olarak vasıflandırdığını söylemek mümkündür. ${ }^{3}$ Çalışma hakkında altı çizilmesi gereken bir diğer konu ise Nihâyetü'l-ereb' in, Memlükler döneminde telif edilen diğer ansiklopedik eserlerle dikkatli bir şekilde mukayese edilmiş olması ve bu literatürdeki benzerlik ve farklılıkların ayrıntılı bir şekilde tartışılmış olmasıdır. Ancak yazar, Millet Kütüphanesi Feyzullah Efendi koleksiyonunda bulunan ve altmış iki ciltte on altı bin varaktan oluştuğu ifade edilen İbn Atıyye el-Avfînin (ö. 906/1501) Keş̧ü̉l-beyân an sifâti'l-hayevân adlı ansiklopedik eserini ${ }^{4}$ çalışmasında kullanmamıştır. Bu eser hakkında yapılacak çalışmalar, Memlükler döneminde telif edilen ansiklopedik eserlerin mahiyetinin daha iyi anlaşılmasına katkı sağlayacaktır.

Muhanna’nın çalışması, Memlükler döneminde neredeyse bütün ilimlerin literatüründe yaşanan zenginleşmenin yanı sıra farklı telif türlerinin ortaya çıkışının sebeplerini ve bunu mümkün kılan arka planı merak eden araştırmacılar için yeni açıklama modelleri teklif etmektedir. Ayrıca çalışma, bir müellif ve eseri üzerine nasıl çalışlabilir sorusunun cevabını arayan, bu konuda metodolojik ve tematik arayış içerisinde olan her alandan araştırmacının istifade edebileceği bir çerçeve sunmaktadır.

3 Muhanna, Encyclopaedia of Islam'ın üçüncü edisyonunda yer alan "Encyclopaedias, Arabic" maddesinin de yazarıdır. Onun bir eseri ansiklopedik kılan hususlar hakkındaki görüşlerini bu çalışma üzerinden de takip edebilmek mümkündür (bk. Muhanna, "Encyclopaedias, Arabic", s. 90-94).

4 Eser hakkında ayrıntılı bilgi için bk. Kireçci, "İbn Atıyye el-Avfî”, 585-87. 


\section{Bibliyografya}

The Digital Humanities and Islamic \& Middle East Studies, ed. Elias Muhanna, Berlin: De Gruyter, 2016.

Kireçci, Mehmet Akif, “İbn Atıyye el-Avfî”, DİA, 2016, Ek-1, s. 585-587.

Muhanna, Elias, "Encyclopaedias, Arabic”, Encyclopaedia of Islam Three, Leiden 2015, fas. 2, s. 90-94.

Sübkî, Tâceddin, Tabakātüş-Şâfiiyyeti’l-kübrâ, thk. Mahmûd Muhammed et-Tanâhî Abdülfettâh Muhammed el-Hulv, I-X, Kahire: Dâru ihyâi'l-kütübi'l-Arabiyye, 138396/1964-76.

Muhammet Enes Midilli, Araştırma Görevlisi İstanbul Üniversitesi İlahiyat Fakültesi

ORCID 0000-0003-0145-3987 DOI 10.26570/isad.571985 